This item was submitted to Loughborough's Research Repository by the author.

Items in Figshare are protected by copyright, with all rights reserved, unless otherwise indicated.

\title{
An adaptive grid to improve the efficiency and accuracy of modelling underwater noise from shipping
}

\section{PLEASE CITE THE PUBLISHED VERSION}

https://doi.org/10.1016/j.marpolbul.2018.04.034

\section{PUBLISHER}

(C) Elsevier

VERSION

AM (Accepted Manuscript)

\section{PUBLISHER STATEMENT}

This work is made available according to the conditions of the Creative Commons Attribution-NonCommercialNoDerivatives 4.0 International (CC BY-NC-ND 4.0) licence. Full details of this licence are available at: https://creativecommons.org/licenses/by-nc-nd/4.0/

\section{LICENCE}

CC BY-NC-ND 4.0

\section{REPOSITORY RECORD}

Trigg, Leah E., Feng Chen, Georgy I. Shapiro, Simon N. Ingram, and Clare B. Embling. 2019. "An Adaptive Grid to Improve the Efficiency and Accuracy of Modelling Underwater Noise from Shipping". figshare. https://hdl.handle.net/2134/33380. 


\title{
An adaptive grid to improve the efficiency and accuracy of modelling underwater noise from shipping
}

\author{
Leah E. Trigg ${ }^{a, *}$, Feng Chen ${ }^{\mathrm{a}, 1}$, Georgy I. Shapiro ${ }^{\mathrm{a}}$, Simon N. Ingram $^{\mathrm{a}}$, Clare B. Embling ${ }^{\mathrm{a}}$ \\ ${ }^{a}$ School of Biological and Marine Sciences, Plymouth University, Plymouth, PL4 8AA, UK
}

\begin{abstract}
Underwater noise pollution from shipping is a significant ecological concern. Acoustic propagation models are essential to predict noise levels and inform management activities to safeguard ecosystems. However, these models can be computationally expensive to execute. To increase computational efficiency, ships are spatially partitioned using grids but the cell size is often arbitrary. This work presents an adaptive grid where cell size varies with distance from the receiver to increase computational efficiency and accuracy. For a case study in the Celtic Sea, the adaptive grid represented a 2 to 5 fold increase in computational efficiency in August and December respectively, compared to a high resolution $1 \mathrm{~km}$ grid. A $5 \mathrm{~km}$ grid increased computational efficiency 5 fold again. However, over the first $25 \mathrm{~km}$, the $5 \mathrm{~km}$ grid produced errors up to $13.8 \mathrm{~dB}$ compared to the $1 \mathrm{~km}$ grid, whereas, the adaptive grid generated errors of less than $0.5 \mathrm{~dB}$.
\end{abstract}

Keywords: Shipping, Underwater Noise, Acoustic Propagation Models

\section{Introduction}

An increasing weight of evidence suggests that noise pollution associated with shipping can have a detrimental impact on marine life (Richardson et al., 1995; Rolland et al., 2012, Wale et al., 2013, Williams et al., 2015, Blair et al. 2016, Dunlop, 2016). As a result, key environmental protection

5 legislation worldwide seeks to regulate noise from shipping (MMPA, 1972; ESA, 1973; European Commission, 2008, 2017; Lucke et al., 2013). Industry and regulatory bodies are often required to robustly quantify the levels of underwater noise emissions associated with shipping for monitoring purposes, and in some circumstances, environmental impact assessment (Merchant et al., 2016). Underwater acoustic propagation models are an essential tool to predict noise for these regulatory and research activities (Dekeling et al., 2014, Farcas et al., 2016, Sertlek et al., 2016).

1 Specifically, acoustic propagation models are primarily used to create ship noise maps Erbe et al. 2014, Marine Management Organisation, 2015). These are important for managers because maps highlight patterns of noise in time and space. It is not practicable to measure noise over large areas using hydrophones. Therefore, to produce a map, it is necessary to predict noise, using a

\footnotetext{
* Corresponding author

Email address: leah.trigg@plymouth.ac.uk (Leah E. Trigg)

${ }^{1}$ Present address: Research Computing Group, ITS, Loughborough University, Loughborough, LE11 3TU, UK
} 
model, at the locations that cannot be measured directly in the environment. It is thought future trends in shipping noise will be small in magnitude; suggested values range from $0.1 \mathrm{~dB}$ per year (Dekeling et al. 2014) to $3.3 \mathrm{~dB}$ per decade (Frisk, 2012). Therefore, it is likely to take many years to detect these trends in measured data. Acoustic propagation modelling can help to reduce the number of years and stations required by allowing spatial averaging of noise levels (Dekeling

et al. 2014). Furthermore, an understanding of noise variability in space can be used to suggest the optimum locations for underwater fixed monitoring equipment (Van der Graaf et al., 2012). Acoustic propagation models are also executed at smaller spatial scales, particularly between one or many sources and a single receiver, in order to validate acoustic propagation models against field measurements as well as benchmark the efficiency and accuracy of different acoustic propagation models (Etter, 2013). Moreover, they can be useful to assess the individual exposure of animals for scientific and regulatory procedures where animal locations are given exactly by telemetry devices or observations (Chen et al. 2017). However, the utilisation of acoustic propagation modelling to undertake such activities is known to have intensive time and computing requirements (Etter, 2013. Wang et al., 2014; Marine Management Organisation, 2015, Sertlek et al., 2016).

Acoustic propagation models tend to be computationally intensive to execute because they are based on a detailed physical representation of acoustic wave propagation and in many cases also account for detailed changes in the environment (range dependent models) (Etter, 2013). Acoustic wave propagation is dependent on sound speed, which is determined by the temperature, hydrostatic pressure and salinity of a water mass (Etter, 2013). Propagation is also influenced by absorption and reflection of waves at boundaries between the water and the surface, the water and the seafloor sediments and different water masses in the ocean (Etter, 2013). However, when predicting shipping noise numerical range dependent models are often neglected in favour of simple geometric spreading laws (Etter, 2013, Marine Management Organisation, 2015). These spreading laws only assume acoustic energy decays logarithmically as sound propagates from source (Urick, 1983). The main attraction of using geometric laws is the speed at which calculations can be conducted (Marine Management Organisation, 2015, Farcas et al., 2016). However, it has been shown that geometric „spreading laws can result in significant errors (Robinson et al., 2014, Farcas et al., 2016). Farcas et al. (2016) demonstrated that when compared to a more complex model (RAM (Collins, 1993)), which allows environmental properties to vary with range from source, the geometric spreading laws underestimated noise close to the source and overestimated noise far from source. This is of particular concern when trying to make predictions for legislation relating to marine ecosystems as it could result in a failure to put in place appropriate mitigation strategies to protect sensitive species. Consequently, in using the geometric laws, users are often making a compromise between computational efficiency and accuracy. As a result, there is a need for methodologies which can reduce the computational costs of executing advanced models so that users can leverage the greater level of realism they provide.

Currently, there are a number of strategies available to make acoustic propagation modelling 
more tractable. For example, it is most pertinent to select, from the numerous available models, an appropriate model for the specific requirements of a study (Farcas et al. 2016). The selection

However, the larger the grid cell size, the less accurate the resulting model output (Erbe et al. 2012b). Larger grid cells do not account for environmental variation. This means that propagation loss values at different points within the cell may vary and the assumption that the propagation loss value at the centre of the cell can be applied to all ships in that cell is incorrect. using acoustic propagation models by designing an adaptive grid to spatially partition ship source data. We present a grid where cell size will vary with distance from the receiver. At ranges close to the receiver, where propagation loss changes very rapidly, a small grid size can be used. However, where ships are far away from the receiver, cell sizes can be much larger due to the of this approach. Theoretically, it improves computational efficiency by reducing the number of calculations required but maintains, or improves, the accuracy of propagation loss estimations when compared to a grid with uniform cell size. Ultimately, this will improve the noise level predictions made using underwater acoustic propagation models for use in ship noise monitoring by making the variability of the environmental characteristics in the study area and the computational power available $($ Etter, 2013$)$. The incorrect choice of a model will compromise both the efficiency and accuracy of the results. Furthermore, an assumption of uniform sound speed, uniform sediment type and uniform bathymetry is often made to simplify propagation calculations (Sertlek et al., 2016). seafloor sediments and bathymetry, these assumptions are not valid. This is often the case in shallow shelf environments where the structure of the water column can be highly stratified (Simpson and Sharples, 2012). In these environments, computationally intensive models that characterise environmental variation using a range and depth dependent approach are required (Jensen, 2011).

For shipping specifically, where there are many disparate noise sources (ships), increases in efficiency can be achieved by spatially partitioning the study area into a grid. Typically, a grid will group ships in square grid cells of a fixed size (Erbe et al., 2014). Applying a grid to the ship data improves efficiency by reducing the number of times the acoustic propagation model must be executed. It is only necessary to calculate propagation loss once from the centre of a grid cell to the cell (Erbe et al., 2012a, 2014). The grid cell size selected for a study is concerned with achieving a realistic execution time for the scale of the study area. Regional studies typically use grid cells between 2 and $5 \mathrm{~km}$ square (Erbe et al., 2014, Marine Management Organisation, 2015), while global studies have used cells of $1^{\circ}$ in longitude and latitude (Porter and Henderson, 2013). The larger the grid cells the fewer calculations required, and therefore, the more efficient the solution.

This study aims to develop a method which produces efficient and accurate noise level predictions logarithmic decay in acoustic energy with range. We then investigate the efficiency and accuracy the implementation of more sophisticated models computationally tractable. 


\section{Methods}

We present an adaptive grid that will spatially group ships. Propagation loss can therefore, be calculated once from the centre of each grid cell to the receiver and applied to all ships in that grid cell. In order to avoid the introduction of error as a result of grouping the ships in this way, ideally propagation loss should be uniform (not vary) across the cell (i.e. the value at the centre of the cell should be representative of the propagation loss at all the points in the cell). In this study, propagation loss was considered uniform when the propagation loss value from the centre of a grid cell to the receiver was approximately equal (given an error of $\pm 1.5 \mathrm{~dB}$ ) to the propagation loss value from each corner of the cell to the receiver. Depending on the distance between the source and the receiver, the maximum grid cell size where propagation loss is uniform will vary. This distance of uniform propagation loss was determined for a number of different grid sizes and used to predict the relationship between these two variables. This study used the relationship between grid size and distance of uniform propagation loss to produce an adaptive grid, and then demonstrated how the adaptive grid reduces computational effort and preserves the accuracy of finer more computationally expensive uniform grids.

\subsection{Case Study Area}

This study focussed on the Celtic Sea region shown by the map in Figure 1. It was considered preferable to use a case study, rather than an idealised site with uniform environmental properties, in order to demonstrate the efficiency and potential limitations of the new method in a real setting. The area is representative of temperate, shallow, coastal shelf waters. The Celtic Sea is seldom deeper than $120 \mathrm{~m}$ and is characterised by the rapid development of a strong thermocline in the summer (April to November) and its slow breakdown in autumn (Pingree, 1980). The region is dynamically active and its water column properties are influenced by multiple mesoscale eddies and fronts (Pingree, 1980). The adaptive grid should be transferable to areas with similar characteristics. Shallow, on-shelf seas are particularly interesting because they play a highly important role in the functioning of the global ocean including biological productivity, economic activity including shipping and the provision of social capital (Simpson and Sharples, 2012).

\subsection{Grid Generation and Analysis for Propagation Loss/Distance Simulations}

In order to determine at what distance from the receiver the propagation loss becomes uniform across a grid cell, a series of propagation loss simulations were conducted at different grid cell sizes. The smallest grid cell size was $0.5 \mathrm{~km}$ and cell size was increased in $0.5 \mathrm{~km}$ increments up to a maximum of $20 \mathrm{~km}$. This range was chosen because it is difficult for the acoustic propagation model to produce reliable results over distances shorter than $0.5 \mathrm{~km}$, and a $20 \mathrm{~km}$ grid cell size was large enough not to result in uniform propagation loss under any of the conditions examined in this study. Figure 2 represents how the grid was structured for these simulations. A fixed receiver was located at one end of a transect shown on the map of the study area (Fig. 1). The grid boxes 


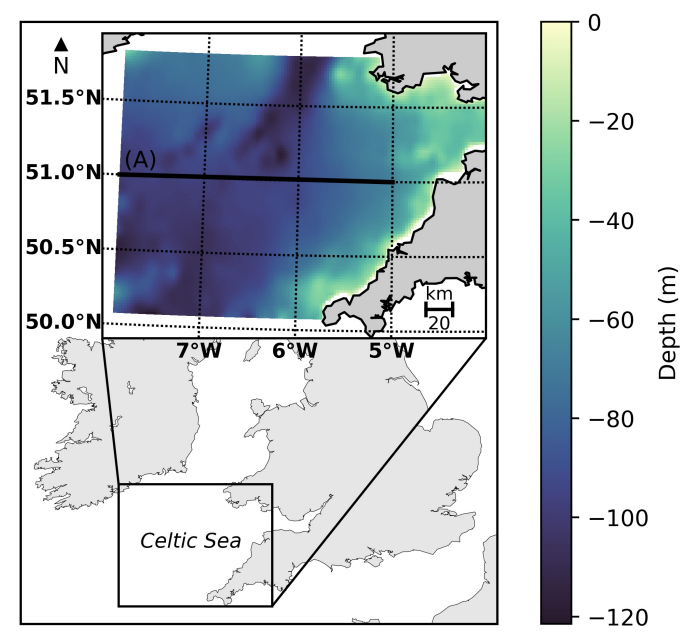

Figure 1: Map of the study area in the Celtic Sea between south-west UK and Ireland. Inset map depicts the bathymetry (National Geophysical Data Center, 2006) of the area (white indicates no data), and the transect (A) along which simulations of propagation loss at different grid sizes were examined. These simulations were undertaken along Transect $\mathrm{A}$ in an east/west and west/east direction, which represented a deepening and shallowing gradient respectively. The transect is approximately $200 \mathrm{~km}$ in length. [FULL PAGE WIDTH, COLOUR]

extended $200 \mathrm{~km}$ horizontally from this point but remained one grid box high vertically (Fig. 22. This was a computationally simple arrangement within the constraints of the study area. As shown in Figure 1, $200 \mathrm{~km}$ extends across the width of the study area, while trying to avoid the most extreme bathymetric changes. This will increase the applicability of results to other shallow shelf seas. The first grid square was always $0.5 \mathrm{~km}$ from the receiver, and grid cells were overlapped horizontally by $0.5 \mathrm{~km}$ in order to increase the resolution of the resulting curves. If they were not overlapped in this manner the $20 \mathrm{~km}$ grid cells would only result in 10 data points compared to the 400 generated by a grid with $0.5 \mathrm{~km}$ cells. Propagation loss was calculated between sources located at each corner and at the centre of every grid cell to the receiver (Fig. 2).

Five propagation loss values were generated for each grid square along the transect - each of the four corners and the centre of the cell. These were plotted against the distance from the centre of the cell to the receiver to produce a propagation loss curve (e.g. Fig. 44. The propagation loss curves from each individual source/receiver pair and the resulting propagation loss and grid square distance curves were smoothed using a low pass second order Butterworth filter $(\mathrm{N}=2, \mathrm{f}=0.01)$. This removes signal noise. The noise is an artefact of the coherent nature of the model used to predict propagation loss and can be removed by smoothing the signal in this manner (Robinson et al. 2014).

Propagation loss was considered uniform across a grid cell when the difference in propagation loss from the four corners fell consistently below a threshold value of $1.5 \mathrm{~dB}$ from the centre. The distance at which this occurred for each grid cell size was plotted to show the relationship between distance of uniform propagation loss and grid cell size. A second or third-order polynomial was fitted to the data points. The polynomial fit was chosen because it minimised the sum of the 
squared residuals for the datasets.

The $1.5 \mathrm{~dB}$ threshold was derived from information on the hearing capabilities of marine mammals and the known error associated with acoustic propagation models. The staircase methodology is used to determine auditory thresholds in marine mammals (Kastak and Schusterman, 1998, 1999 Popov et al., 2013: Cunningham and Reichmuth, 2016). This process plays back sound at different frequencies to determine when the animal responds. It is common for playback amplitude to be decreased in steps of $4 \mathrm{~dB}$ for every correct response and then increased in steps of $2 \mathrm{~dB}$ after the first missed response (Kastak and Schusterman, 1998, 1999, Cunningham and Reichmuth, 2016). This suggests, therefore, that at some frequencies marine mammals will be able to discriminate between sounds that differ in amplitude by $2 \mathrm{~dB}$. As a result, some threshold level less than $2 \mathrm{~dB}$ would be appropriate. Hanna and Rost (1981) compared a parabolic equation model (the type of model used in this study) to measurements taken in the ocean. They reported mean errors of 1.5 $\mathrm{dB}$, whilst Jensen (2011) compared different types of acoustic propagation model using a standard problem and reported 1.1 to $1.6 \mathrm{~dB}$ mean differences between the models. As a result, it could be expected that propagation loss values may vary by that magnitude as a result of model error rather than non-uniformity within a cell, consequently, $1.5 \mathrm{~dB}$ was considered an appropriate threshold.

The simulations took place along Transect A (Fig. 1) in two directions under a number of different conditions. Firstly, the receiver was placed at the westerly end of the transect and the grid was generated, as shown in Figure 2, to the east. In this configuration the bathymetry shallows in the east and sound propagation is downslope. In the second configuration the sound propagation was reversed so the receiver was placed at the eastern extent of the transect and the grid was generated in a westerly direction. Sound would travel upslope in this configuration. Simulations are also repeated under summer and winter conditions because the water column is strongly stratified in the summer due to the development of a thermocline. This can significantly influence propagation loss (Shapiro et al. 2014). As a result, in summer the results are shown for a receiver depth of $20 \mathrm{~m}$ and $60 \mathrm{~m}$ to reflect conditions above and below the thermocline. The source depth was $7 \mathrm{~m}$ for all conditions. This is a typical estimated source depth for a large commercial ship (McKenna et al., 2012).

\subsection{Acoustic Propagation Model}

The parabolic-equation model RAMSurf (http://oalib.hlsresearch.com/PE/ramsurf/, Collins 1993) was used to calculate propagation loss between each sound source and the receiver. This model is widely used for range dependent, low frequency, shallow water scenarios $(\overline{E t t e r}, 2013)$. In this study, the horizontal and vertical step parameters for the acoustic model were fixed at $50 \mathrm{~m}$ and $0.5 \mathrm{~m}$ respectively for all simulations. These values ensure a convergent solution to the model given the frequency tested and ensure that all simulations are comparable. Simulations were conducted at a frequency of $125 \mathrm{~Hz}$. This frequency is one of the centre frequencies for the $1 / 3$ octave bands that are given by the EU Marine Strategy Framework Directive as important for monitoring shipping 


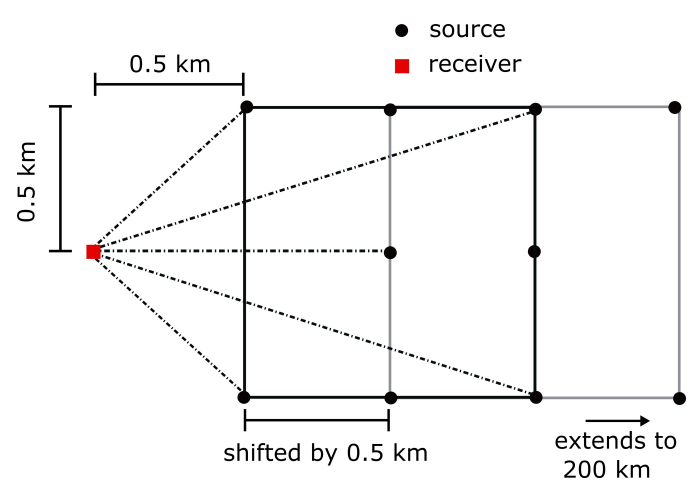

Figure 2: Schematic of generated grid for calculating the distance between source and receiver at which propagation loss is uniform (i.e. approximately equal at all points in a grid cell). The receiver is shown as a square point located at one end of the transect. A hypothetical source was placed at the corner of each grid cell and at the centre of the cell. The grid extended the length of the $200 \mathrm{~km}$ transect. Each new grid cell was placed $0.5 \mathrm{~km}$ further along the transect than the last to increase the resolution of the resulting propagation loss curves. Propagation loss was calculated from every source to the receiver directly as shown by the dash-dot lines. The value of propagation loss at the receiver (square) is compared and when the values at the corner are within $\pm 1.5 d B$ of the centre, the propagation loss within that cell is considered uniform. [1 COLUMN WIDTH]

noise (European Commission, 2008, 2017).

The three-dimensional oceanographic model POLCOMS was used to provide temperature and salinity data along each transect (Holt and James, 2001). The oceanographic model had a horizontal resolution of $2 \mathrm{~km}$ and 30 vertical layers. This was used to calculate sound speed profiles in $2 \mathrm{~km}$ increments along the transects. This model, its implementation and associated bathymetric data are described in detail by Chen et al. (2013). The speed of sound through the water, given the temperature, salinity and depth was calculated using the nine term equation given by Mackenzie (1981). Seabed sediment data were provided by the EMODnet Geology project (http://www.emodnetgeology.eu). The distribution of sediment types throughout the study area are shown in Figure 3 . The geoacoustic parameters for each sediment type were selected from known geoacoustic values in the following sources, Hamilton (1980), Lurton (2002) and NURC (2008). The sediment grain size, and percentage of clay, gravel and sand for each EMODnet sediment type (Long, 2006) was used to select an appropriate geoacoustic value from the above sources given a similar sediment type description. The selected geoacoustic parameters for each sediment type are given in Table 1 .

Table 1: Geoacoustic parameters passed to RAMSurf model. Appropriate values were selected from published geoacoustic studies as indicated below. $C_{p}$ - P-wave sound speed, $\alpha$ - P-wave attenuation. [FULL PAGE WIDTH]

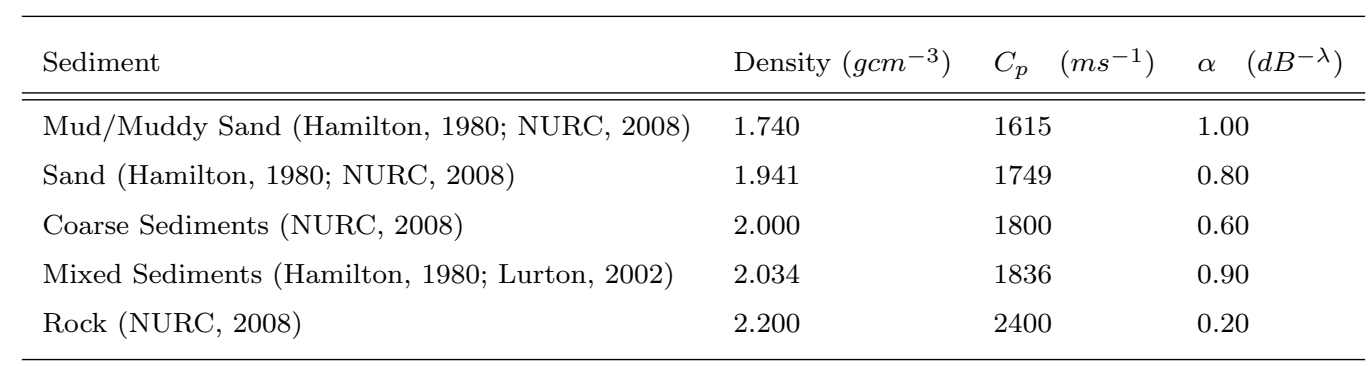




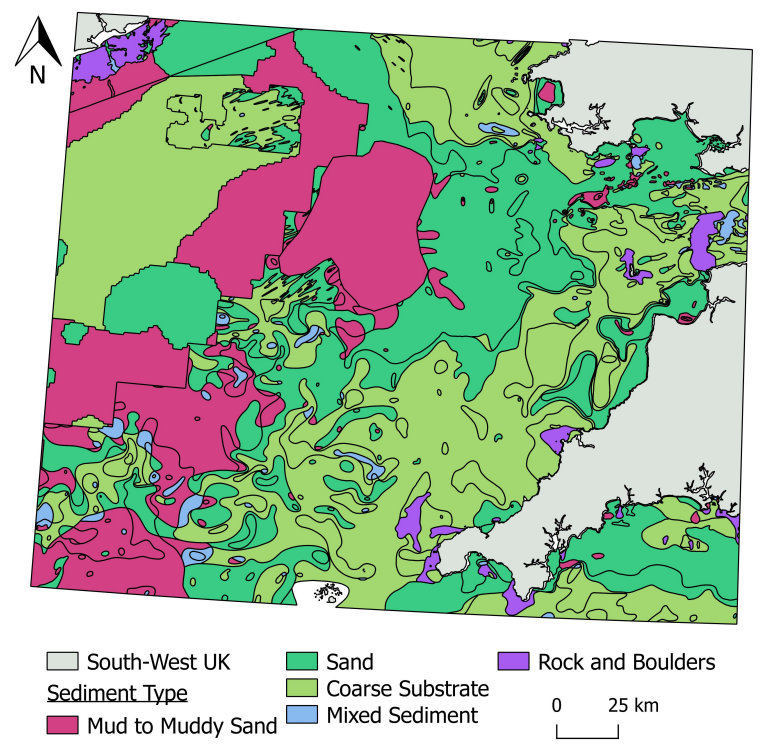

Figure 3: Map of the sediment types in the Celtic Sea using five sediment classes as described by Long (2006). Information modified from EMODnet Europe seabed substrate data, scale 1:250000 (CEMODnet Geology, European Commission, 2016, downloaded 2016-07-21) [FULL PAGE WIDTH, COLOUR] situation arises skip to the next grid size that can be drawn in the available distance i.e. skip using $4.0 \mathrm{~km}$ cells and use $4.5 \mathrm{~km}$ grid cells. The relationship shows these should extend to $42.7 \mathrm{~km}$, 
and therefore, two rows can be used between 33.7 and $42.7 \mathrm{~km}$. Secondly, the next grid size (in propagation loss for the adaptive grid and the $5 \mathrm{~km}$ grid were linearly interpolated to the points of the $1 \mathrm{~km}$ grid. As a result it was possible to calculate the absolute difference in the smoothed propagation loss between each point on the grid. The interpolation was a computational exercise to ensure that the matrices containing the results had the same dimensions. This ensured they could

\section{Results}

\subsection{Grid Size and Distance Relationship}

In order to determine the distance of uniform propagation loss for grid cell sizes between 0.5 and $20 \mathrm{~km}$ a number of propagation loss simulations were conducted. The resulting propagation 
loss curves are shown in Figure 4 . The figure shows the propagation loss from each corner and the centre of the grid cells for the upslope transects with a receiver depth of $20 \mathrm{~m}$ and grid cell sizes of $1 \mathrm{~km}, 5 \mathrm{~km}$ and $20 \mathrm{~km}$. The results for the downslope condition and plots for August at a receiver depth of $60 \mathrm{~m}$ are shown in Supplementary Material Figures 1 and 2. Figure 4 demonstrates that when the source and receiver are close together $(0-25 \mathrm{~km})$ the propagation loss at each of the corners and at the centre of the grid cell differs, at grid cell sizes of $1 \mathrm{~km}$, by $\sim 3 \mathrm{~dB}$ and at larger grid sizes by $\sim 15 \mathrm{~dB}$. This difference in propagation loss decreases as the distance between the source and receiver increases. As described in Methods (Sec. 2.2), propagation loss within the grid cell is considered uniform when propagation loss from the centre of the grid cell to the receiver and each corner to the receiver is approximately equal $( \pm 1.5 \mathrm{~dB}$ from centre value). The results (Fig. uniform across the cell increases. This is illustrated in Figure 4 for both December and August. The distance of uniform propagation loss (the point at which each line comes together as one) is $25 \mathrm{~km}$ for the $1 \mathrm{~km}$ cells in December and August (Fig. 4a, 4b), and $\sim 50 \mathrm{~km}$ for $5 \mathrm{~km}$ grid cells in December (Fig. 4c). In August there was no point at which propagation loss became uniform for the $5 \mathrm{~km}$ grid cells. Figure $4 \mathrm{~d}$ appears to be uniform for a short distance but then this uniformity breaks down again. This is most likely a result of the variability in water column properties in the Celtic Sea during summer. This was not the case for the downslope condition suggesting that the distance of uniform propagation loss is further influenced by the bathymetry of the transect. Figure $4 \mathrm{e}$ and $4 \mathrm{f}]$ show that at grid cell sizes of $20 \mathrm{~km}$ the difference in propagation loss between each point does not come below the $1.5 \mathrm{~dB}$ threshold even when source and receiver are separated by $200 \mathrm{~km}$.

The distance at which propagation loss becomes uniform across the grid cell was extracted for all conditions at each grid cell size. This is shown in Figures 5 and 6 for December upslope and downslope at a receiver depth of $20 \mathrm{~m}$, and August upslope and downslope at a receiver depth of $20 \mathrm{~m}$ and $60 \mathrm{~m}$. In December at $200 \mathrm{~km}$ the indicated grid box size is between 10 and $14 \mathrm{~km}$ (Fig. 5a, 5b). However, in August the indicated grid box size at $200 \mathrm{~km}$ is between 4 and $8 \mathrm{~km}$ for upslope and downslope at $20 \mathrm{~m}$ and $60 \mathrm{~m}$ (Fig. 5c 5d Fig. 6a, 6b). The smaller grid cell sizes in August are most likely due to the variability in ocean properties during August in the Celtic Sea. Sound propagation is determined by oceanographic conditions, and changes in properties such as temperature and salinity will result in changes in propagation loss values. Small grid cell sizes are required to capture this variation. The Celtic Sea is well mixed in the winter months (Pingree 1980). A more uniform sea in December allows the use of larger grid cells.

In order to predict the expected grid cell size at different distances, the relationship between distance of uniform propagation loss and grid size was characterised by a second or third-order polynomial. This generally indicates an initial rapid increase in cell size over a short distance, followed by a period of less rapid change where a certain cell size can be used for greater distances. The maximum distance considered here was $200 \mathrm{~km}$. The graph could be extended to greater distances in larger seas. However, the contribution of ships over $200 \mathrm{~km}$ distance from the receiver 
is likely to have negligible impact on the receiver. For example, in this study at $200 \mathrm{~km}$ propagation loss levels are between approximately 110 - $140 \mathrm{~dB}$ and sound pressure levels of ships are typically between 170 - $190 \mathrm{~dB}$ re $1 \mu \mathrm{Pa}$ at $1 \mathrm{~m}$ (McKenna et al., 2012, Veirs et al., 2015) resulting in possible noise level contributions only between 30 and $80 \mathrm{~dB}$ re $1 \mu \mathrm{Pa}$ at this distance. 


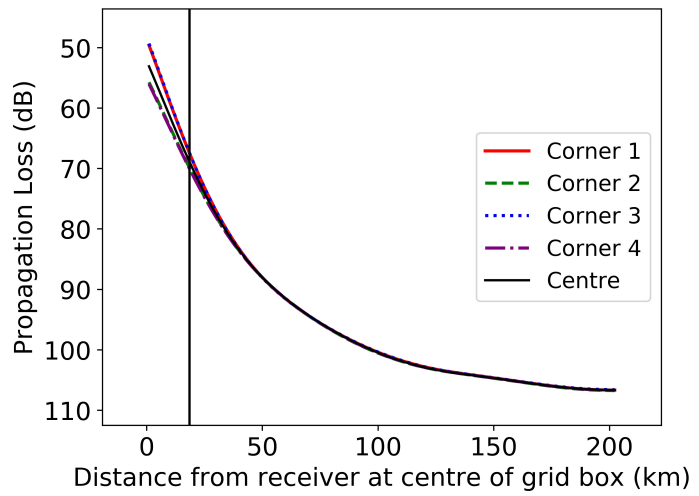

(a) December $1 \mathrm{~km}$

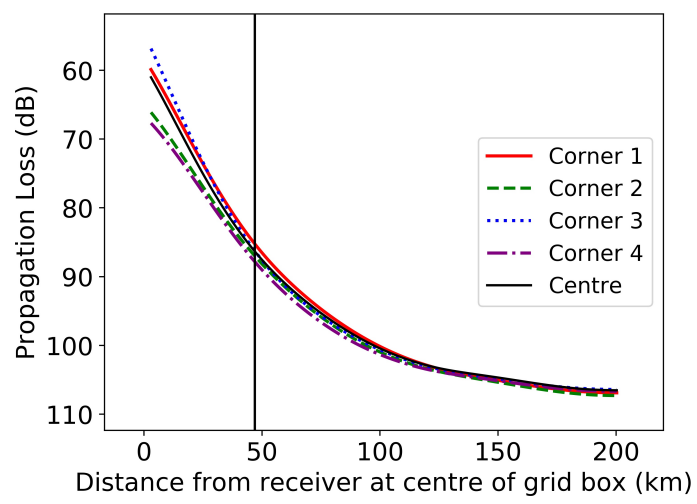

(c) December $5 \mathrm{~km}$

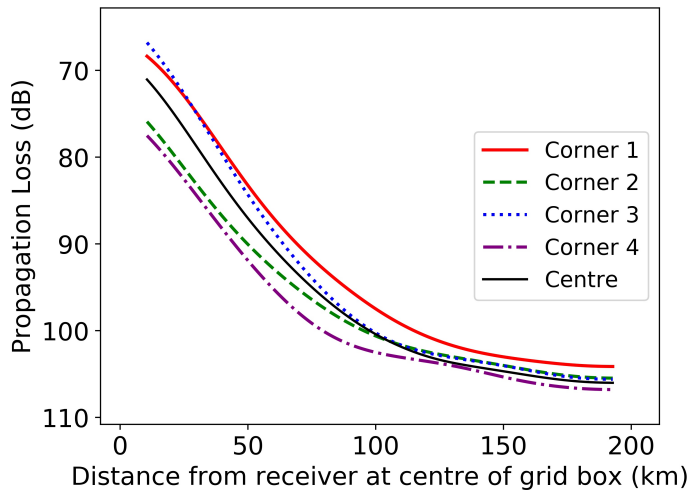

(e) December $20 \mathrm{~km}$

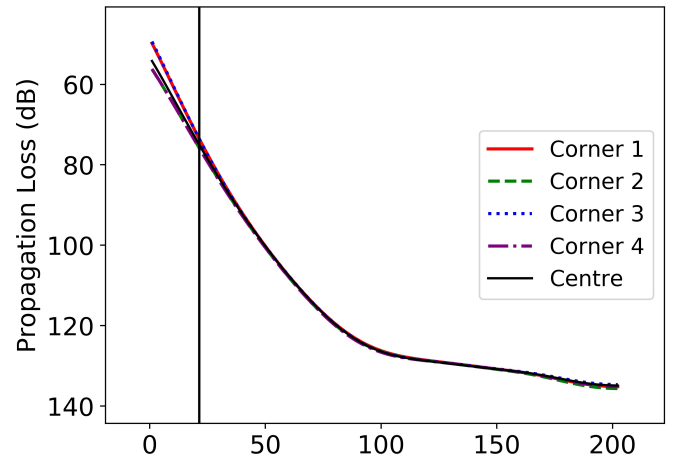

Distance from receiver at centre of grid box $(\mathrm{km})$

(b) August $1 \mathrm{~km}$

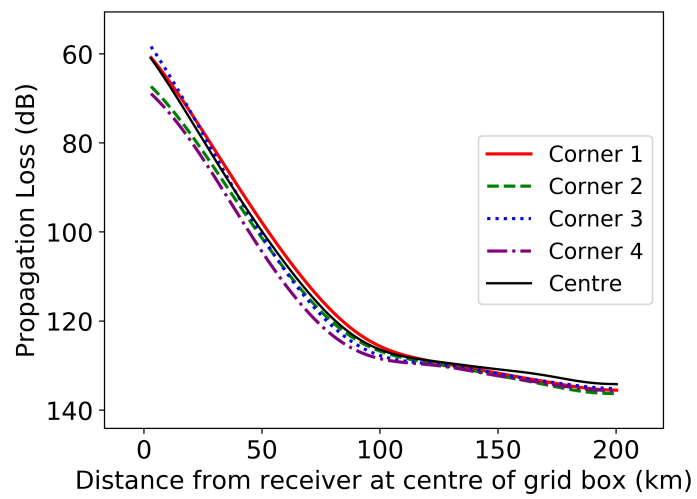

(d) August $5 \mathrm{~km}$

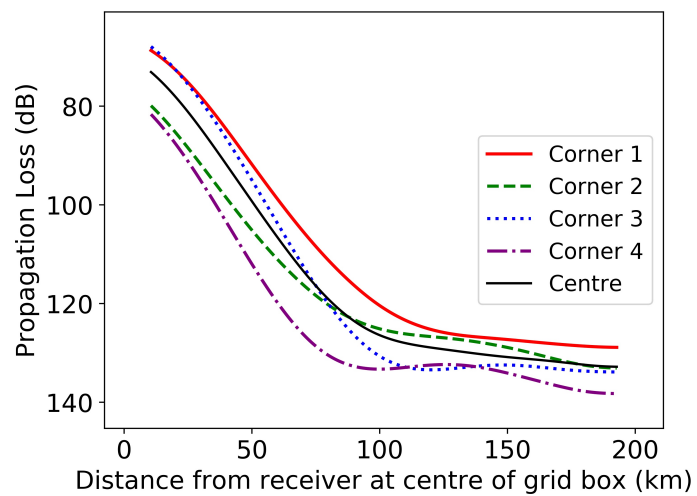

(f) August $20 \mathrm{~km}$

Figure 4: Propagation loss at each corner and the centre of grid cells for the upslope condition for grid cell sizes of 1 , 5, and $20 \mathrm{~km}$ in December and August at a receiver depth of $20 \mathrm{~m}$. When the corner values come to within $1.5 \mathrm{~dB}$ of the centre consistently, propagation loss is considered uniform (vertical black line). As distance between the source and receiver increases the difference in propagation loss between each corner and centre decreases until uniform. As the grid sizes become larger the distance of uniform propagation loss becomes much greater. For the $20 \mathrm{~km}$ grid cell sizes (e,f) there is still a large difference between each corner and centre at $200 \mathrm{~km}$ and at no point is propagation loss considered uniform. It is also possible to note that in December maximum propagation loss is $\sim 110 \mathrm{~dB}$ but in August this value is $~ 140 \mathrm{~dB}$. [FULL PAGE WIDTH] 


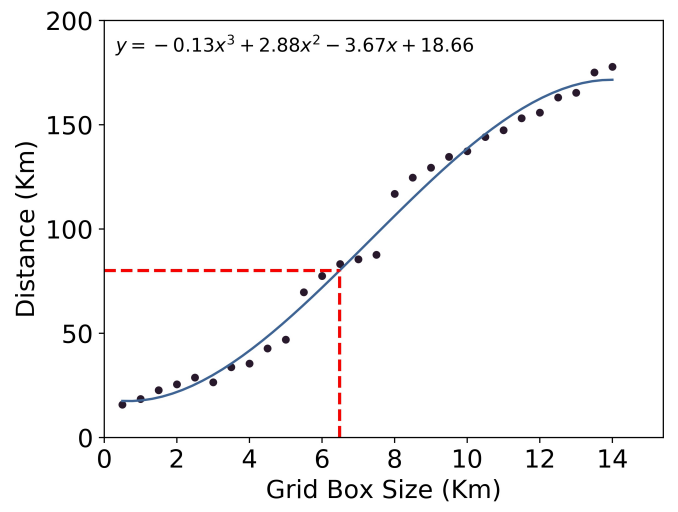

(a) December Upslope $20 \mathrm{~m}$

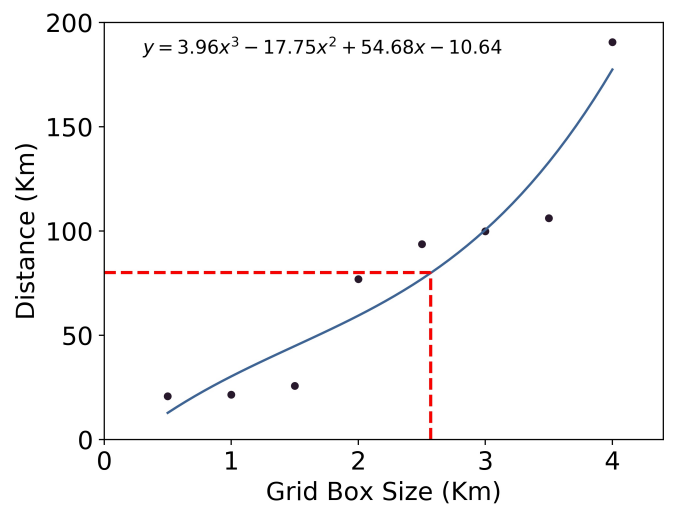

(c) August Upslope $20 \mathrm{~m}$

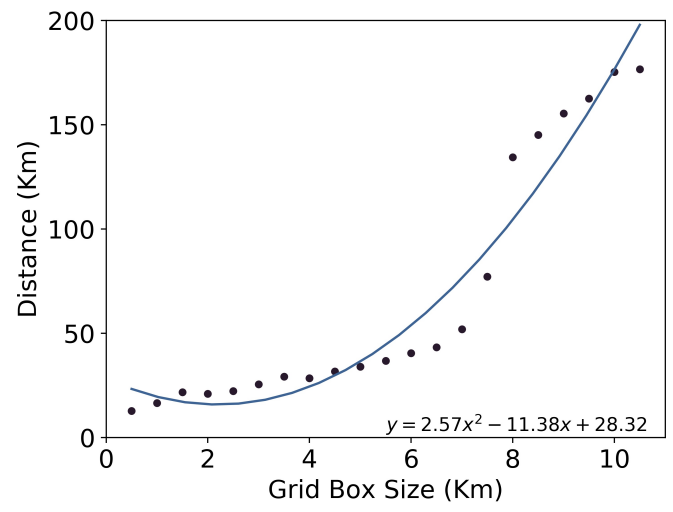

(b) December Downslope 20m

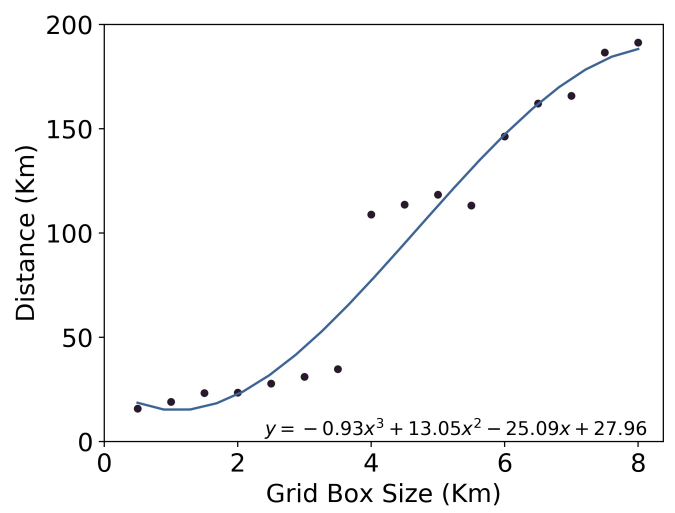

(d) August Downslope $20 \mathrm{~m}$

Figure 5: The distance at which the difference in propagation loss between each corner and the centre of the cell is below $1.5 \mathrm{~dB}$ for different grid cell sizes. Plots are shown for the upslope and downslope conditions at a receiver depth of $20 \mathrm{~m}$ for December and August. Points are smoothed using a 2nd or 3rd order polynomial. The maximum grid cell size shown ( $\mathrm{x}$ axis), is the maximum grid cell size for which propagation loss becomes uniform for that condition. This is greater in December than August. The dashed line indicates the maximum grid cell size that would be used when the source and receiver are separated by a distance of $80 \mathrm{~km}$ for the two example adaptive grids shown in this study. [FULL PAGE WIDTH] 


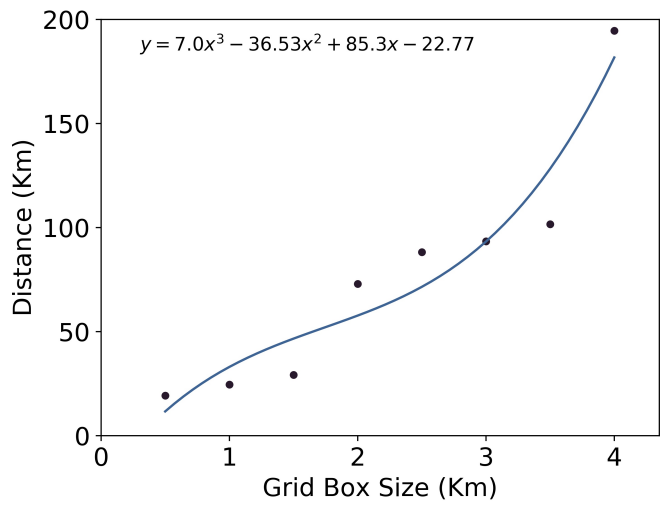

(a) August Upslope $60 \mathrm{~m}$

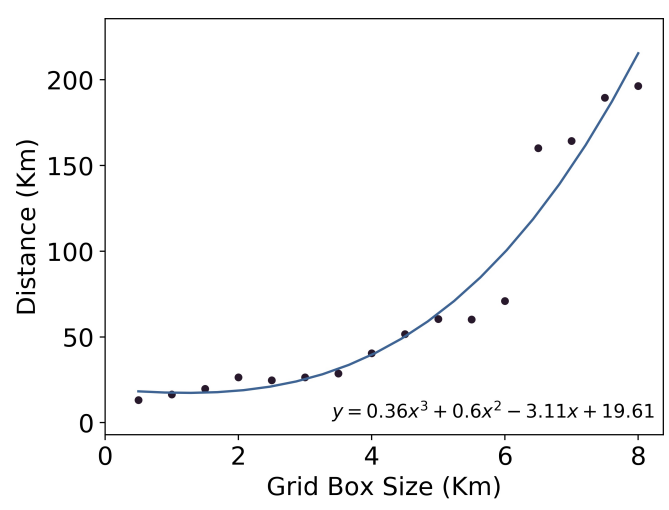

(b) August Downslope $60 \mathrm{~m}$

Figure 6: The distance at which the difference in propagation loss between each corner and the centre of the cell is below $1.5 \mathrm{~dB}$ for different grid cell sizes. Plots are shown for the upslope and downslope conditions in August for a receiver depth of $60 \mathrm{~m}$. Points are smoothed using a 3rd order polynomial. The maximum grid cell size shown is the maximum grid cell size for which propagation loss becomes uniform for that condition ( $\mathrm{x}$ axis). This is greater for the downslope condition than the upslope condition. [FULL PAGE WIDTH]

\subsection{Adaptive Grid}

The adaptive grids were created based on the relationships between distance and grid size shown in Figures 5 and 6. However, as discussed in Methods Section 2.4, these relationships change very rapidly over the first fifty kilometres and consequently, the resulting grids are conservative representations of these relationships. This conservative approach has meant the resulting adaptive grids tend to take on one of two forms despite the different relationships generated for each condition. The adaptive grids for the upslope December and August conditions at a receiver depth of $20 \mathrm{~m}$ are shown in Figure 7 as examples of these two forms. The adaptive grids for the remaining conditions are shown in Supplementary Material Figures 3 and 4 . The adaptive grid shown in Figure $7 \mathrm{a}$ is based on the relationship shown in Figure $5 \mathrm{a}$. The adaptive grid commences with 1 $\mathrm{km}$ grid cells and steps in half kilometre increments up to $3.5 \mathrm{~km}$ grid cells. However, at $80 \mathrm{~km}$ in Figure $5 \mathrm{a}$ the dashed line indicates that the grid box size should be closer to $\sim 6 \mathrm{~km}$. It would be possible to achieve this by using an approach for grid development (See Methods Sec. 2.4), which moves to larger grid sizes more quickly. This approach was not taken here in order to preserve, as much as possible, the accuracy of the adaptive grid, which is important for applications such as environmental impact assessment and decision making. It was often not possible to just skip to a larger grid cell size because the size used needed to be a multiple of the total length of each grid edge. For example, one edge of the final adaptive grid produced here is $160 \mathrm{~km}$. The next grid size used would need to divide this distance exactly (e.g. $32,5 \mathrm{~km}$ boxes) to create a complete grid. As a result, the achievable grid cell size was an interplay between maximum cell size indicated by the grid size/distance relationship and the constraints of generating a continuous grid of square grid cells.

Figure $7 \mathrm{~b}$ shows the adaptive grid for the upslope August relationship as displayed in Figure $5 \mathrm{c}$ 
This grid covers the same area as the other adaptive grids developed, and used the same conservative grid development approach. The maximum grid cell size achieved is only $2 \mathrm{~km}$ with the majority of the grid using a $1.5 \mathrm{~km}$ grid cell size. When compared with December, these smaller grid cell sizes reflect the different relationships produced in summer and winter as a result of the different environmental conditions in the Celtic Sea at this time. Furthermore, the dashed line (Fig. 5c) indicates that at $80 \mathrm{~km}$ a $2.5 \mathrm{~km}$ grid cell size would be optimal suggesting that the conservative approach has again led to the implementation of smaller grid cell sizes. 


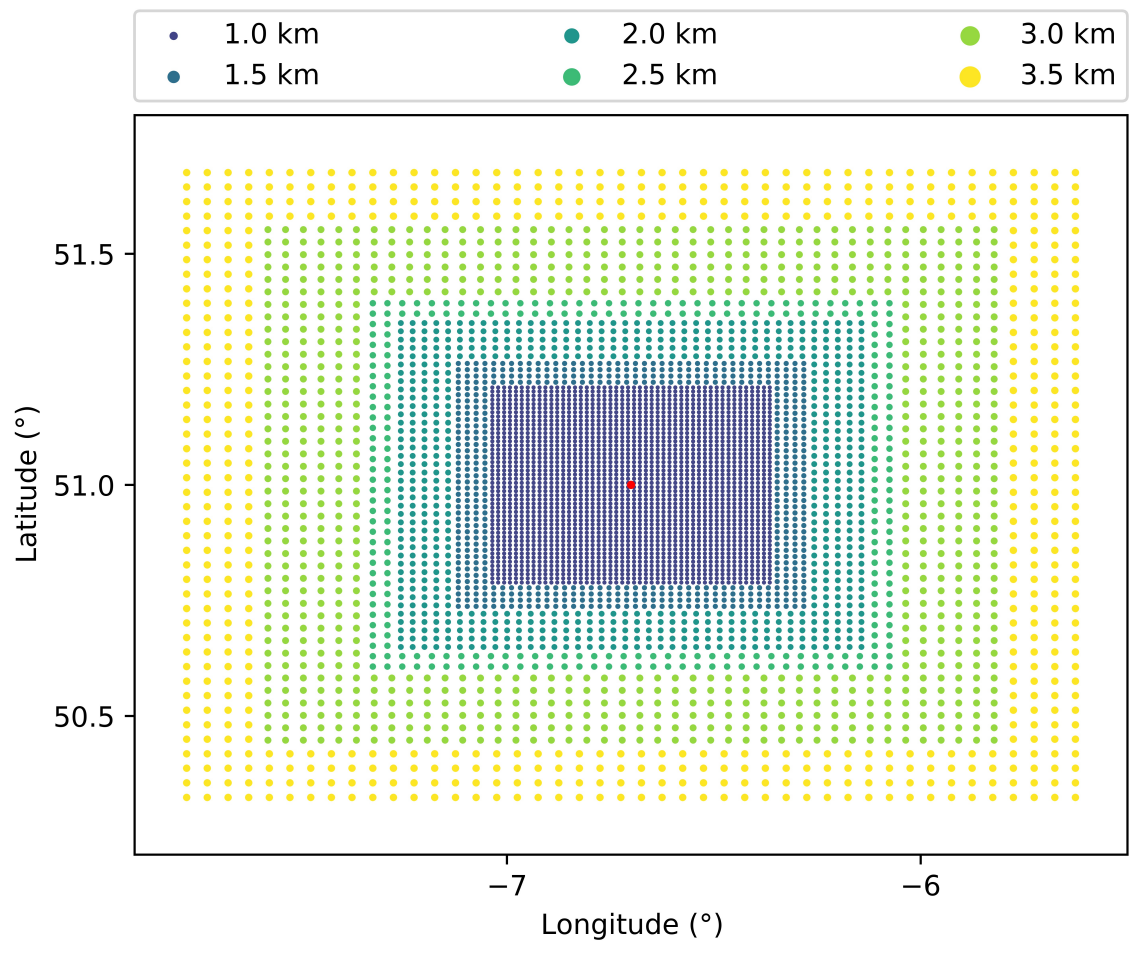

(a) Upslope December 20m

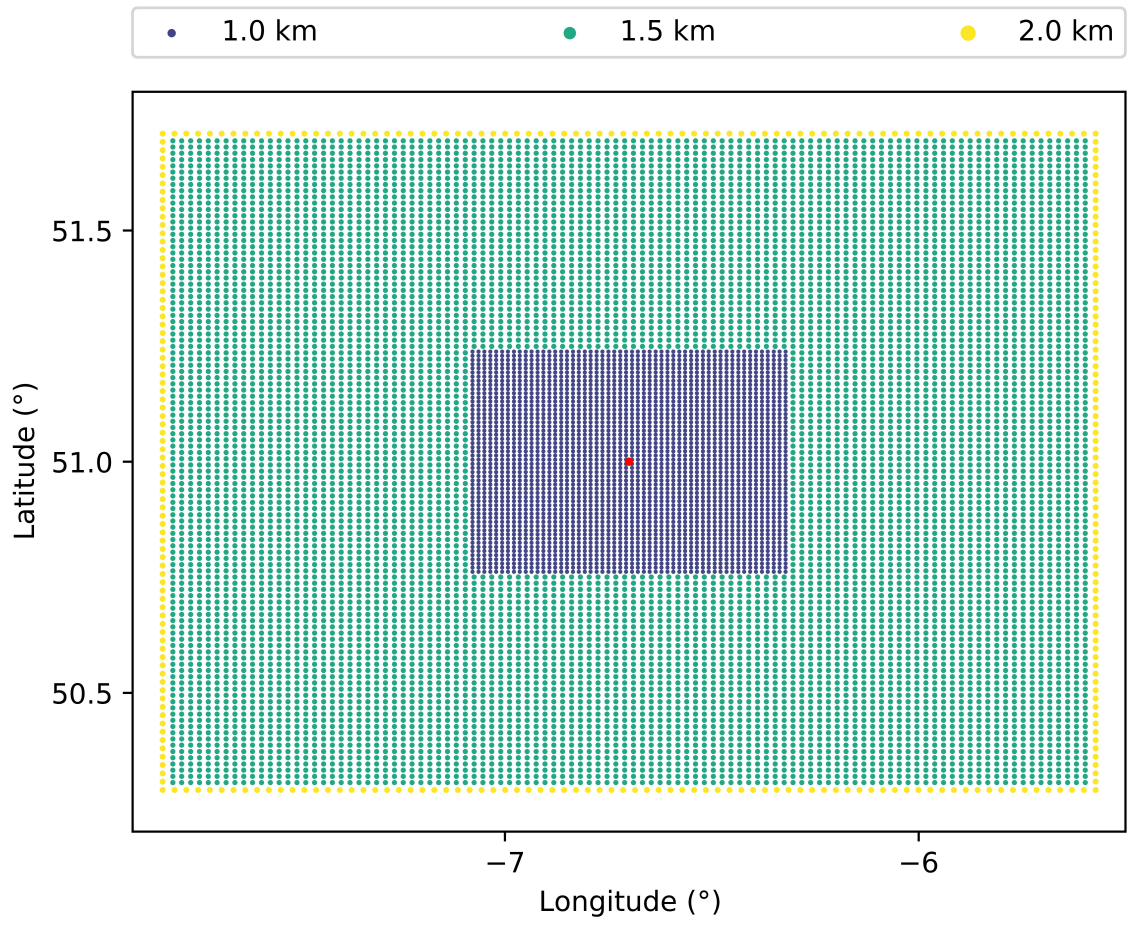

(b) Upslope August 20m

Figure 7: Example adaptive grids for a $160 \times 160 \mathrm{~km}$ area of the Celtic Sea for the upslope conditions in December and August at a receiver depth of $20 \mathrm{~m}$. Each dot indicates the centre of a cell, the size of which is shown in the key above the grid. Red dot indicates the receiver and each color indicates a new grid size. [FULL PAGE WIDTH, COLOUR] 


\subsection{Computational Efficiency of Adaptive Grid}

In order to assess the computational efficiency of the adaptive grid, it was compared to two grids with $1 \times 1 \mathrm{~km}$ cells and $5 \times 5 \mathrm{~km}$ cells respectively. Table 2 shows the number of points in these two grids and the adaptive grids under the different conditions over a $160 \times 160 \mathrm{~km}$ area. The $1 \mathrm{~km}$ grid has 25 times more points than the $5 \mathrm{~km}$ grid. The adaptive grid achieves a 5 -fold reduction in the number of points in a $1 \mathrm{~km}$ grid for December and a 2 -fold reduction in the number of points in a 1 $\mathrm{km}$ grid in August. However, the adaptive grid has approximately five times the number of points as the $5 \mathrm{~km}$ grid in December and approximately twelve times the number of points in August.

Table 2: The number of points and hence model executions required for the adaptive, $1 \mathrm{~km}$ and $5 \mathrm{~km}$ grids over a $160 \times 160 \mathrm{~km}$ area. Depth refers to receiver depth and direction to the direction of sound propagation. The maximum distance between the receiver and edge of the grid is $80 \mathrm{~km}$ in a straight line north, south, east or west. The number of points is used as a proxy for computational cost. The number of points does not change with month, receiver depth or direction of sound propagation for the grids with $1 \mathrm{~km}$ and $5 \mathrm{~km}$ grid cell sizes. [1 COLUMN WIDTH]

\subsection{Accuracy of Adaptive Grid}

The adaptive grid provides an important computational saving over the grid with $1 \times 1 \mathrm{~km}$ uniform grid cells but is not more efficient than using a grid with $5 \times 5 \mathrm{~km}$ cells. As a result, it is necessary to examine more closely the advantages of using the adaptive grid, the most pertinent of which, is the accuracy of the grid. Variation in propagation loss within the cell can result in overor under-estimation of the total propagation loss. The potential advantage of the adaptive grid is that it can achieve computational efficiencies without a decrease in accuracy by using a smaller grid cell size close to the receiver and a larger cell size further away. Figures $8 \mathrm{a}$ and $8 \mathrm{~b}$ show the smoothed propagation loss at the receiver for each transect in the grid. It is possible to see that over the first 25 kilometres the $1 \mathrm{~km}$ and adaptive grid differ by a maximum of $0.5 \mathrm{~dB}$. This is due to the adaptive grid taking the form of the $1 \mathrm{~km}$ grid for much of this range. The $1 \mathrm{~km}$ and adaptive grid differ from the $5 \mathrm{~km}$ grid by between 3 and $13.8 \mathrm{~dB}$ in this range. At greater distances the difference between all three grid sizes is reduced and all vary by not more than $2 \mathrm{~dB}$. Figures $8 \mathrm{a}$ and $8 \mathrm{~b}$ also show the propagation loss calculated using the geometric spreading model. The difference between this and the RAMSurf model, which is a typical model for shallow low frequency 
problems, is $\sim 10 \mathrm{~dB}$ in December close to the receiver but as large as $\sim 20 \mathrm{~dB}$ far from the receiver in August. The 15 log model for both conditions consistently underestimates propagation loss and hence overestimates noise. The opposite is true of the $20 \log$ model in December (Fig. 8a). It consistently overestimates propagation loss and underestimates noise levels. However, in Figure $8 \mathrm{~b}$ the 20 log model overestimates propagation loss and hence underestimates noise close to the receiver but at greater distances the opposite is true.

It is also possible to view how the accuracy of the propagation loss compares over the spatial grid. The absolute difference in the propagation loss between the $1 \mathrm{~km}$ grid and the $5 \mathrm{~km}$ grid for December and August are shown in Figures 9a and 9b respectively. To demonstrate the change in propagation loss clearly, values greater than or equal to the threshold of $1.5 \mathrm{~dB}$ are shown in black and those less than $1.5 \mathrm{~dB}$ are shown in white. It is possible to see that some of the greatest differences in propagation loss calculations can be found when source and receiver are close together at the centre of the map. Figures $9 \mathrm{c}$ and $9 \mathrm{~d}$ show the absolute difference in propagation loss at the receiver between the $1 \mathrm{~km}$ grid and adaptive grid for December and August respectively. When compared with the previous figures of the same month $9 \mathrm{a}$ and $9 \mathrm{~b}$ it is possible to see that the adaptive grid reduces the number of points that differ from the $1 \mathrm{~km}$ grid by $1.5 \mathrm{~dB}$ or greater. This is particularly evident when source and receiver are close together. This demonstrates the improvement in accuracy achieved by the adaptive grid. In December and August 3.5\% and 16.1\% of the 25600 points in the $1 \mathrm{~km}$ grid have a difference of greater than or equal to $1.5 \mathrm{~dB}$ respectively when compared to the $5 \mathrm{~km}$ grid. This is in contrast to $1.4 \%$ and $9.2 \%$ when comparing the $1 \mathrm{~km}$ and the adaptive grid in December and August respectively.

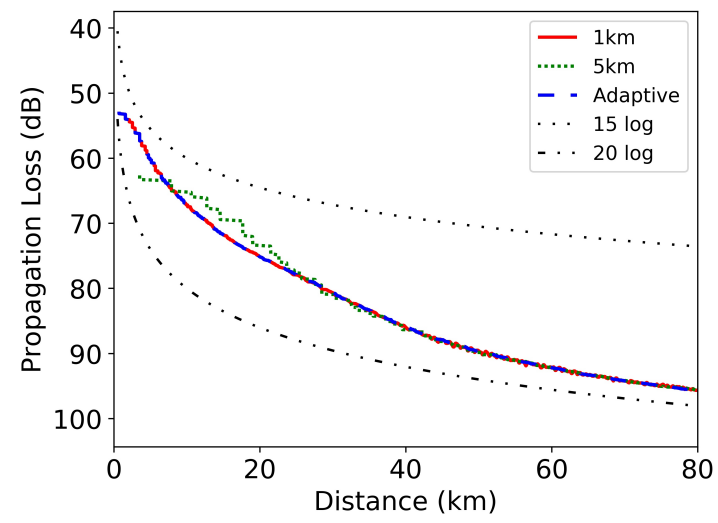

(a) December

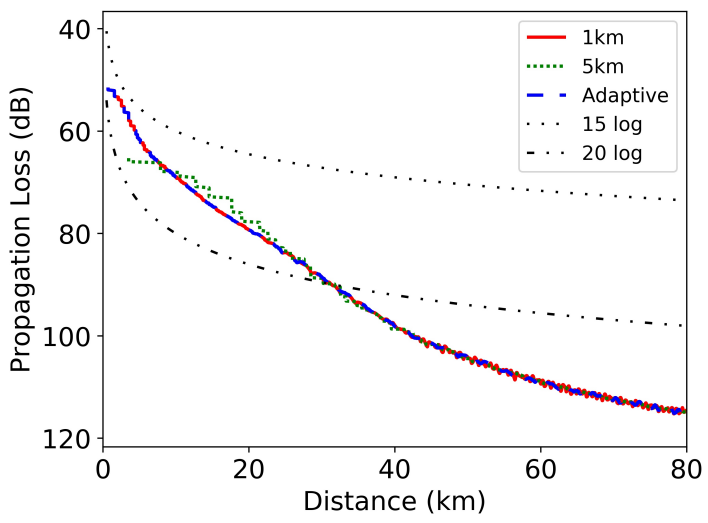

(b) August

Figure 8: Smoothed propagation loss (Butterworth filter $\mathrm{N}=2, \mathrm{f}=0.01$ ) for all points in the $1 \mathrm{~km}, 5 \mathrm{~km}$ and Adaptive grid for the upslope condition in December and August at a receiver depth of $20 \mathrm{~m}$. Over the first $25 \mathrm{~km}$, the $5 \mathrm{~km}$ grid differs by up to $13.8 \mathrm{~dB}$ from the $1 \mathrm{~km}$ grid while the adaptive grid only differs by a maximum of $0.5 \mathrm{~dB}$. [FULL PAGE WIDTH, COLOUR] 


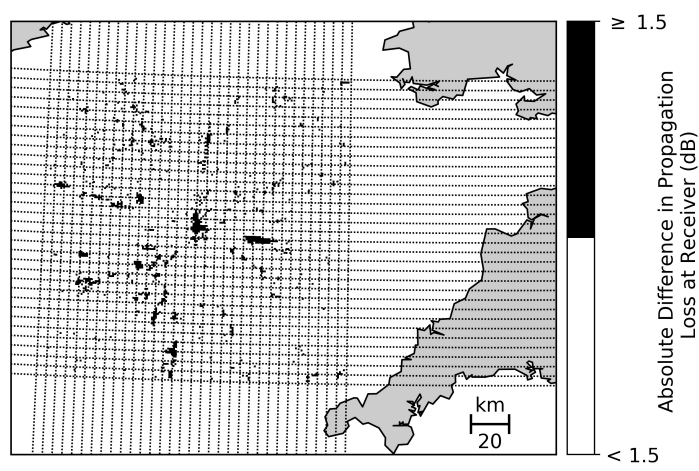

(a) December $1 \mathrm{~km}-5 \mathrm{~km}$

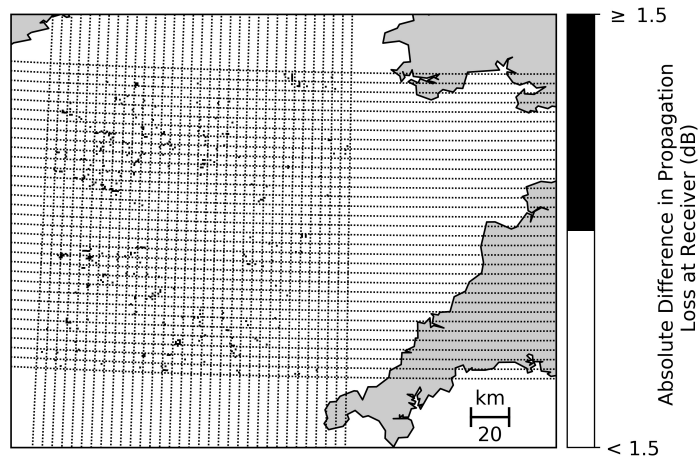

(c) December $1 \mathrm{~km}$ - Adaptive

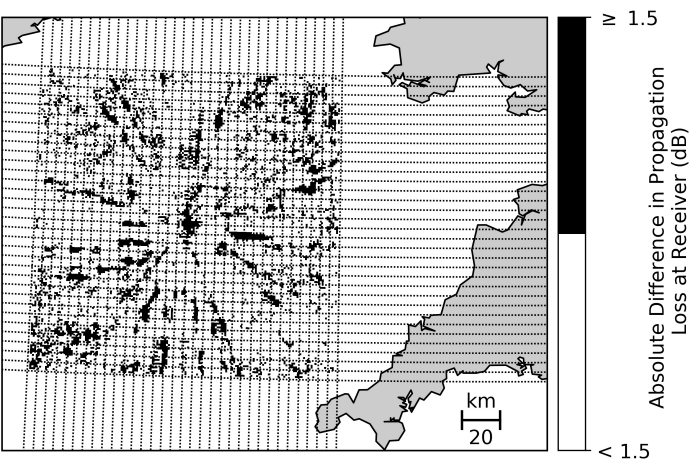

(b) August $1 \mathrm{~km}-5 \mathrm{~km}$

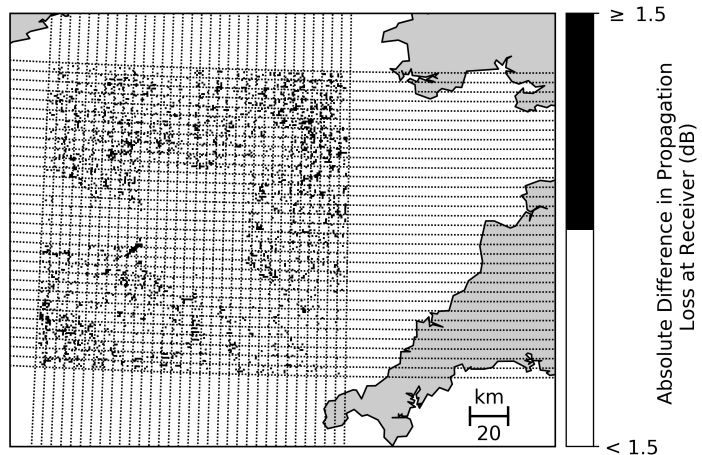

(d) August $1 \mathrm{~km}$ - Adaptive

Figure 9: The absolute difference in propagation loss at the receiver between the $1 \mathrm{~km}$ grid and the $5 \mathrm{~km}$ grid, and the $1 \mathrm{~km}$ grid and the adaptive grid. Black points indicate where the difference in absolute propagation loss at the receiver is greater than or equal to $1.5 \mathrm{~dB}$. Receiver was located at centre of grid. Grid lines mark uniform $5 \mathrm{~km}$ cells. There are 25600 points in the grid. The percentage of these with error greater than or equal to $1.5 \mathrm{~dB}$ are (a) $3.5 \%$, (b) $16.1 \%$ (c) $1.4 \%$ and (d) $9.2 \%$. [FULL PAGE WIDTH]

\section{Discussion}

This study aimed to reduce the computational cost and improve the accuracy of modelled ship noise level predictions by replacing the aggregation of ships using a uniform grid with an adaptive grid. The results demonstrate that, over a $160 \times 160 \mathrm{~km}$ area the adaptive grid reduces the computational cost 5 fold in December and between 2 and 5 fold in August when compared to a $1 \mathrm{~km}$ grid. The $5 \mathrm{~km}$ grid reduces computational cost 5 fold again. However, over the first $25 \mathrm{~km}$ the $5 \mathrm{~km}$ grid produces errors of up to $13.8 \mathrm{~dB}$ when compared to the accurate but inefficient $1 \mathrm{~km}$ grid. The newly developed adaptive grid generates much smaller errors of less than $0.5 \mathrm{~dB}$ while demonstrating high computational efficiency. At greater distances the difference in propagation loss between the $1 \mathrm{~km}$ grid and the adaptive grid increases to similar levels as the difference between the $1 \mathrm{~km}$ and $5 \mathrm{~km}$ grids. The adaptive grid reduced the computational cost of obtaining noise level predictions while maintaining a higher level of accuracy in the area close to the receiver when compared to the $5 \mathrm{~km}$ grid.

The reduction in computational cost achieved by the adaptive grid is potentially a realisable 
reduction in the monetary cost of completing environmental impact assessments, monitoring activities and scientific studies that can be recouped by the businesses or universities that fund such activities. This saving is most likely to be found due to a reduction in the amount of time taken to complete the activity, which could also increase the speed of decision making by management organisations. It is difficult to define exactly how much of a time saving can be achieved by using the adaptive grid because baseline times are dependent on many factors such as the model used, computational power available and the efficiency of code used to generate input files and execute the model. However, the time savings are likely to be of the same magnitude as the reduction in the number of transects that must be calculated. For example, if it is assumed that to complete a single transect takes two seconds, the $1 \mathrm{~km}$ grid with 25600 transects would be complete in approximately 14 hours, the $5 \mathrm{~km}$ grid with 1024 transects would take 34 minutes and for a typical adaptive grid of 5356 transects (Results Tbl. 22) it would take 3 hours. In this scenario the adaptive grid would reduce the time required in comparison to the $1 \mathrm{~km}$ grid by 11 hours.

Furthermore, the ability to improve the efficiency of acoustic propagation model predictions is important to facilitate the implementation of more sophisticated models as part of regular ship noise mapping and assessment activities (Marine Management Organisation, 2015). Farcas et al. (2016) demonstrated that when compared to the model RAM, geometric spreading laws, which are widely used as part of legislative compliance assessments because they are quick, underestimate noise close to the source but overestimate noise far from the source. The results here show that the geometric spreading laws $(P L=N \log (r))$ followed similar trends when compared to the results from the RAMSurf model, although whether it under- or over-estimated noise varied depending on the value of $\mathrm{N}$ chosen. The implementation of the spreading laws, in this Celtic Sea setting, may have negative implications for sensitive marine species and industry. Where noise is underestimated, even a precautionary approach to mitigation, may not be sufficient to put in place the correct protection for a species. This is particularly important at close range where noise levels, and hence potential harm are greatest (Richardson et al., 1995, Farcas et al., 2016). In general it is also important not to overestimate noise to avoid negative impacts such as restricting the growth of economically important industries or the cost of implementing mitigation strategies that are not required (Farcas et al. 2016). In shallow coastal environments where the source and receiver are very close together the introduction of more accurate models, which take account of important environmental variation, is a key mechanism by which the accuracy of these noise level predictions can be improved (Farcas et al. 2016). The results of this study demonstrate that the adaptive grid can be utilised as part of a methodological toolbox for ship noise modelling that can make models based on advanced physical representations of propagation (e.g. RAM and Bellhop) more practical. This will only be enhanced by continued efforts to improve the acoustic propagation models themselves and the development of new models with reduced computational execution times (Sertlek and Ainslie, 2014).

For ship noise mapping, sources are often represented using a density map, which spatially and temporally partitions the data (Erbe et al., 2012a; Porter and Henderson, 2013, Marine Management 
Organisation, 2015). The resulting maps are usually based on annual or monthly averages of ship numbers, which involve considerably fewer calculations than weekly or daily maps for the same time frame. However, there is known temporal variability in ship noise at these finer scales Merchant et al. 2014: Neenan et al., 2016). This can be addressed using the adaptive grid, which improves the efficiency and accuracy of spatial partitioning, potentially allowing a greater range of temporal variability to be captured for the same level of computational effort.

The level of accuracy required by acoustic propagation models can be considered, to some extent, dependent on the acceptable levels of uncertainty as defined by the user. The results of modelling activities are generally used to assess the impact of noise on marine ecosystems and may feed into planning applications, legislative compliance reporting and scientific conclusions regarding noise impacts (Hastie et al., 2015, Farcas et al., 2016, Chen et al., 2017). As a result, the over- or under-estimation of noise levels can have real consequences for marine life or industry. Crucially, the adaptive grid is more accurate than the $5 \mathrm{~km}$ grid when source and receiver are within 25 $\mathrm{km}$ of each other. This spatial relationship between a noise source and a receiver is important for assessing the impact of noise on marine life (Ellison et al., 2012). Richardson et al. (1995) explained the 'zones of influence' concept based on the distance between a receiver and a single source. The theoretical zones suggest at what distances sound is audible, can cause behavioural disturbance, avoidance, hearing loss and injury in marine mammals. While this concept has its critics (Ellison et al. 2012, Van der Graaf et al., 2012), it is useful for highlighting the importance of accurate noise level predications when source and receiver are very close together. Erbe (2002) suggested that a received level of $120 \mathrm{~dB}$ re $1 \mu \mathrm{Pa}$ would cause a behavioural response in $50 \%$ of cetaceans. To use the adaptive grid as an example, propagation loss estimates when source and receiver are within $25 \mathrm{~km}$ is between approximately 50 and $80 \mathrm{~dB}$. Typical broadband source levels for large ships are between 170 and $190 \mathrm{~dB}$ re $1 \mu \mathrm{Pa}$ at $1 \mathrm{~m}$ (McKenna et al. 2012, Veirs et al., 2015) resulting in approximate received ship noise levels for the adaptive grid presented here between 90 and $140 \mathrm{~dB}$ re $1 \mu \mathrm{Pa}$ within $25 \mathrm{~km}$, which is firmly in the region of the $120 \mathrm{~dB}$ re $1 \mu \mathrm{Pa}$ predicted to cause behavioural disturbance (Erbe, 2002). The rate of propagation loss at these close distances will change relative to the environmental conditions, but it serves to highlight that this zone is important for marine mammal protection when considering the impact of underwater noise from shipping. In addition, Erbe and Farmer (2000) estimated zones of influence for beluga whales (Delphinapterus leucas) in relation to icebreaker ships and reported a zone of audibility between 38 and $78 \mathrm{~km}$, masking between 14 and $71 \mathrm{~km}$ and temporary auditory threshold shift (TTS) between 1 and 4 $\mathrm{km}$. Corresponding estimates were also presented by Erbe (2002). They examined whale watching boats travelling at high speed $(51 \mathrm{~km} / \mathrm{h})$. These boats were audible to whales over ranges of $16 \mathrm{~km}$, masked calls over ranges of $14 \mathrm{~km}$ and could produce TTS over ranges of $400 \mathrm{~m}$. The appropriate zones of influence will be specific to noise source, species and environmental conditions but accurate noise level predictions are a vital ingredient to make sure these zones are appropriate. The proposed zones reported above show that the close distances $(0-25 \mathrm{~km})$ over which the adaptive grid offers 
improved noise level predictions are key for the protection of marine mammals.

The results demonstrate that the grid size/distance curves are generally characterised by a $3 \mathrm{rd}$ order polynomial curve. The shape of each curve is determined by the underlying bathymetry, and the structure of the fronts and thermocline in the water column (Urick, 1983, Lurton, 2002, Shapiro et al. 2014). It is possible to see that the overall shape of each curve is influenced by the gentle upslope or downslope bathymetry and its interplay with water column structure. There is a marked difference between the relationships in August and those in December, specifically, for the upslope condition. In August, the variation in the water column is much greater, and therefore, much smaller grid sizes are required to capture this variation. The maximum grid size is $4 \mathrm{~km}$ in August compared to $14 \mathrm{~km}$ in December. There are similar albeit less extreme differences visible under the downslope condition. In December grid cell sizes reach a maximum of $10 \mathrm{~km}$ but only $8 \mathrm{~km}$ in August. This difference in the downslope condition is not reflected in the results for computational efficiency (Results, Tbl. 2 because the difference is absorbed during the conservative approach to grid development (Methods Sec. 2.4. As a result there is little difference in the adaptive grids under the downslope condition. In contrast, the difference in the upslope condition is quite marked, resulting in an opportunity to use separate grids for December and August allowing greater accuracy to be preserved in August and efficiency to be maximised in December. These observations have important implications for the applicability of these relationships to settings outside the Celtic Sea.

In order for the results to be applicable to a new area, this location should have the same general shallow water characteristics. In addition, careful consideration should be given to the structure of the water column. If the area develops a thermocline in summer, it is important to switch to a grid with finer grid cells. As described above, the conservative approach to grid development has, to some extent, removed the differences between the grids for the downslope condition. Despite the different grid size/distance relationships (Fig. 56 ) for all the downslope conditions and the December upslope condition, Table 2 shows that the number of points in all cases are between 5036 and 5356. This similarity suggests that the adaptive grids developed here may be applicable to a number of other temperate shallow water settings. However, given the influence of upslope propagation, they would not account for very steep or sudden changes in bathymetry, and therefore, there must be careful consideration of the physical properties of any new site before the adaptive grid is applied. In an area that is very different to the Celtic Sea where many projects in the same area are likely to be required, developing specific relationships between grid cell size and distance may be warranted.

There are a number of possible applications for the adaptive grid. It can be utilised, as in this study, around a single receiver to validate field measurements and assess the exposure of individual animals (Robinson et al., 2014, Chen et al., 2017). Alternatively, it can be implemented around multiple receivers to undertake ship noise mapping. The test scenarios in this study have placed a fixed receiver at the centre of the grid. If the receiver was to move or there was more than one receiver, as would be the case when examining marine fauna or creating a ship noise map, 
it would be necessary to regenerate the adaptive grid around each receiver at each location. It is important to note that the grid generation process does not require the acoustic propagation model to be executed. In this study, grid generation at a new receiver location took on average 0.09 seconds. In comparison to the estimated theoretical time saving of 11 hours per receiver achieved by implementing an adaptive grid, there is still a considerable improvement in efficiency. When creating a ship noise map, as with maps using traditional grids, propagation loss must be calculated between each source/receiver pair (Erbe et al. 2012b). In traditional mapping activities, one transect may pass through several receivers, reducing the number of transects required. This will occur less often when using an adaptive grid because grid cells will be offset. Despite differences in the methodologies, there will still be net savings in computational efficiency because the adaptive grid also reduces the number transects required. It is difficult to suggest a general level of efficiency that can be achieved because the reduction in transects depends on the size of the area mapped. The largest cell sizes in the adaptive grid provide the greatest benefit (i.e. reduction in the number of transects compared to smaller uniform grids) but these are only used at greater distances. Therefore, the larger the area mapped, the greater the improvement seen in efficiency. Importantly, when noise source and receiver move around the environment, the regeneration of the grid would always result in the smallest grid sizes around the receiver, and therefore, provides the finest estimations of propagation loss when the source and receiver are close together regardless of the oceanographic variation in an area. The ability to maintain a fine grid structure when source and receiver are close together improves accuracy when compared to uniform grid sizes, as shown in this study.

Nevertheless, depending on the execution time of the model for a single transect, such ship noise mapping can still be a time consuming process. Potentially, there is an opportunity to find a greater level of efficiency by increasing grid cell size more quickly over certain ranges. The variation in propagation loss in space is determined by range from the source (i.e. geometry) and absorption, over which environmental properties can have a significant influence (Urick, 1983). It is environmental influences such as temperature and bathymetry that result in deviations from the general geometric spreading laws that describe propagation in homogeneous waters (Urick 1983). In such environmentally uniform areas, there is the potential for the use of much coarser adaptive grids, which change to larger grid cells more quickly, based on geometry alone. It may be possible to use coarser grids and account for environmental variation by using some factor to weight the propagation loss values. However, it is likely to require significant work to determine this relationship. Alternatively, in a region where the environmental variables do not differ in space the implementation of range independent models with faster execution times (e.g. a normal modes model) may improve the efficiency of the results and make mapping exercises with multiple receivers more tractable (Porter and Henderson, 2013). However, in environmentally variable regions using such models and coarser grids, even though faster than RAM, will often produce inaccurate results. Specifically, in the Celtic Sea it is known that spatial and seasonal variation in the temperature structure of the water column results in marked differences in propagation loss calculations (Shapiro 
et al. 2014).

As mentioned above, the adaptive grid presented here is a conservative implementation of the distance and grid size relationship. There is also the possibility to find greater computational efficiencies by using different approaches to adaptive grid development. The method of grid generation used in this study was governed by the shape of the adaptive grid and the individual cells, which are at present, square. As a result, the distance/grid size relationship is only maintained along the north/south and east/west axis. Where the relationship breaks down, the accuracy of the results may be compromised, which could account for some of the variation seen between the $1 \mathrm{~km}$ grid and adaptive grid when source and receiver are separated by larger distances $(25-80 \mathrm{~km})$. In the future it may be possible to implement curved grids that maintain the relationship throughout the 360 degree axis. Particularly, grids generated from triangular cells have the ability to be flexible and could smoothly migrate between cell sizes avoiding the use of $0.5 \mathrm{~km}$ steps in cell size, and maintaining the observed relationship between grid cell size and distance at all points on the grid (Chen et al. 2006).

This study has been concerned with modelling approaches to predict underwater noise levels. However, acoustic propagation models are not a perfect reflection of reality. Hanna and Rost (1981) compared a parabolic equation model to measurements in the ocean and found mean errors of $1.5 \mathrm{~dB}$. Ship noise predictions are also a multi-stage process and this study does not consider the errors that arise during these other stages, such as difficulties in characterising ship source levels (Wales and Heitmeyer, 2002, Wittekind, 2014, Farcas et al., 2016) and uncertainties in the environmental input data. However, the ability to predict noise levels for management purposes is invaluable (Boyd et al. 2011, Van der Graaf et al., 2012). It is not logistically possible to deploy hydrophones for real-world measurements at all points in the ocean. The use of a model allows managers and regulatory bodies to make informed decisions about the likely impact of shipping noise and determine noise hotspots and quiet zones. The adaptive grid can assist in realising the potential of acoustic propagation models in management settings by helping to make it a more efficient and practical process with the highest levels of accuracy possible.

\section{Conclusion}

This study aimed to improve the efficiency and accuracy of ship noise predictions using acoustic propagation models by developing a method which uses an adaptive grid to spatially partition ships. Over an area of $160 \times 160 \mathrm{~km}$ the adaptive grid reduced the number of model executions 5 fold in December and between 2 and 5 fold in August. A similar level of computational efficiency was achieved with a coarse $5 \mathrm{~km}$ grid. However, over the first $25 \mathrm{~km}$ the $5 \mathrm{~km}$ grid produces errors of up to $13.8 \mathrm{~dB}$ when compared to the $1 \mathrm{~km}$ grid. The newly developed adaptive grid generated much smaller errors of less than $0.5 \mathrm{~dB}$ but also demonstrated high computational efficiency. As a result, the adaptive grid provides the ability to maintain or improve the accuracy of noise level predictions, and at the same time, increase the efficiency of the modelling process. This is a potentially important 
reduction in the cost of undertaking modelling activities and can help management stakeholders use the most accurate and sophisticated modelling approaches. This can help safeguard sensitive marine ecosystems from noise pollution and impose fair restrictions on industry by improving the underwater noise predictions that inform management activities.

\section{Acknowledgements}

This work was supported by a Plymouth University Research Studentship and the Plymouth comments improved the manuscript.

\section{Declaration}

Declarations of interest: None

\section{Contributions}

All authors have approved the submission.

Conceived the study: G. Shapiro, F. Chen, L. Trigg, C. Embling, S. Ingram

Simulations and Data Analysis: L. Trigg, F.Chen

Advised Analysis: G. Shapiro, F. Chen, C. Embling, S. Ingram

Wrote manuscript: L. Trigg

590

Reviewed and Edited Manuscript: G. Shapiro, F. Chen, C. Embling, L. Trigg 


\section{References}

Blair, H. B., Merchant, N. D., Friedlaender, A. S., Wiley, D. N., Parks, S. E., 2016. Evidence for ship noise impacts on humpback whale foraging behaviour. Biology Letters 12 (8), 419-427.

Boyd, I. L., Frisk, G., Urban, E., Tyack, P., Ausubel, J., Seeyave, S., Cato, D., Southall, B., Weise, M., Andrew, R., Akamatsu, T., Dekeling, R., Erbe, C., Farmer, D., Gentry, R., Gross, T., Hawkins, A., Li, F., Metcalf, K., Miller, J. H., Moretti, D., Rodrigo, C., Shinke, T., 2011. An international quiet ocean experiment. Oceanography 24 (2), 174-181.

Chen, C., Beardsley, R. C., Cowles, G., 2006. An unstructured grid, finite-volume coastal ocean model (fvcom) system. Oceanography 19, 78-89.

Chen, F., Shapiro, G., Bennett, K., Ingram, S., Thompson, D., Vincent, C., Russell, D., Embling, C., 2017. Shipping noise in a dynamic sea: a case study of grey seals in the Celtic Sea. Marine Pollution Bulletin 114 (1), 372-383.

Chen, F., Shapiro, G., Thain, R., 2013. Sensitivity of Sea Surface Temperature Simulation by an Ocean Model to the Resolution of the Meteorological Forcing. ISRN Oceanography 2013, 1-12.

Collins, M. D., 1993. A splitstep Padé solution for the parabolic equation method. The Journal of the Acoustical Society of America 93 (4), 1736-1742.

Cunningham, K. A., Reichmuth, C., 2016. High-frequency hearing in seals and sea lions. Hearing Research 331, 83-91.

Dekeling, R. P., Tasker, M. L., Van der Graaf, A. J., Ainslie, M., Andersson, M. H., André, M., Borsani, J. F., Brensing, K., Castellote, M., Cronin, D., Dalen, J., Folegot, T., Leaper, R., Pajala, J., Redman, P., Robinson, S. P., Sigray, P., Sutton, G., Thomsen, F., Werner, S., Wittekind, D., Young, J. V., 2014. Monitoring Guidance for Underwater Noise in European Seas. Part II - Monitoring Guidance Specification. JRC Scientific and Policy Reports EUR 26555 EN, Publications Office of the EU, Luxembourg.

Dunlop, R. A., 2016. The effect of vessel noise on humpback whale, Megaptera novaeangliae, communication behaviour. Animal Behaviour 111, 13-21.

Ellison, W. T., Southall, B. L., Clark, C. W., Frankel, A. S., 2012. A new context-based approach to assess marine mammal behavioral responses to anthropogenic sounds. Conservation Biology : The Journal of the Society for Conservation Biology 26 (1), 21-28. (Orcinus Orca), based on an Acoustic Impact Model. Marine Mammal Science 18 (2), 394-418.

Erbe, C., Farmer, D. M., 2000. Zones of impact around icebreakers affecting beluga whales in the Beaufort Sea. The Journal of the Acoustical Society of America 108 (3), 1332-1340. 
Erbe, C., MacGillivray, A., Williams, R., 2012a. Mapping cumulative noise from shipping to inform marine spatial planning. The Journal of the Acoustical Society of America 132 (5), EL423.

Erbe, C., MacGillivray, A., Williams, R., 2012b. Mapping Ocean Noise: Modelling Cumulative Acoustic Energy from Shipping in British Columbia to Inform Marine Spatial Planning. WWF Canada and Curtin University, Perth, Australia.

Erbe, C., Williams, R., Sandilands, D., Ashe, E., 2014. Identifying modeled ship noise hotspots for marine mammals of Canada's Pacific region. PloS One 9 (3), e89820.

ESA, 1973. US Endangered Species Act. 16 U.S.C. Sec. 1531 et seq. URL http://www.nmfs.noaa.gov/pr/laws/esa/text.htm

Etter, P., 2013. Underwater Acoustic Modeling and Simulation, 4th Edition. CRC Press, Boca Raton.

European Commission, 2008. Directive 2008/56/EC of the European Parliament and of the Council of 17 June 2008 establishing a framework for community action in the field of marine environmental policy (Marine Strategy Framework Directive).

URL http://eur-lex.europa.eu/legal-content/EN/TXT/?uri=CELEX : 32008L0056

European Commission, 2017. Commission Decision (EU) 2017/848 of 17 May 2017 laying down criteria and methodological standards on good environmental status of marine waters and specifications and standardised methods for monitoring and assessment, and repealing Decision 2010/477/EU (notified under document C/2017/2901.

URL https ://eur-lex.europa.eu/legal-content/en/TXT/?uri=CELEX : 32017D0848

Farcas, A., Thompson, P. M., Merchant, N. D., 2016. Underwater Noise Modelling for Environmental Impact Assessment. Environmental Impact Assessment Review 57, 114-122.

Frisk, G. V., 2012. Noiseonomics: The relationship between ambient noise levels in the sea and global economic trends. Scientific Reports 2 (1), 2-5.

Hamilton, E. L., 1980. Geoacoustic modeling of the sea floor. The Journal of the Acoustical Society of America 68 (5), 1313-1340.

Hanna, J. S., Rost, P. V., 1981. Parabolic equation calculations versus North Pacific measurement data. The Journal of the Acoustical Society of America 70 (2), 504-515.

Hastie, G. D., Russell, D. J., McConnell, B., Moss, S., Thompson, D., Janik, V. M., 2015. Sound exposure in harbour seals during the installation of an offshore wind farm: predictions of auditory damage. Journal of Applied Ecology 52 (3), 631-640. 
Holt, J. T., James, I. D., 2001. An s coordinate density evolving model of the northwest european continental shelf: 1. model description and density structure. Journal of Geophysical Research: Oceans 106 (C7), 14015-14034.

Jensen, F. B., 2011. Computational Ocean Acoustics, 2nd Edition. Springer.

Kastak, D., Schusterman, R., 1999. In-air and underwater hearing sensitivity of a northern elephant seal (Mirounga angustirostris). Canadian Journal of Zoology 77 (11), 1751-1758.

Kastak, D., Schusterman, R. J., 1998. Low-frequency amphibious hearing in pinnipeds: methods, measurements, noise, and ecology. The Journal of the Acoustical Society of America 103 (4), $2216-2228$.

Long, D., 2006. BGS detailed explanation of seabed sediment modified folk classification. URL http://www.emodnet-seabedhabitats.eu/PDF/GMHM3_Detailed_explanation_of_ seabed_sediment_classification.pdf

Lucke, K., Winter, E., Lam, F. P., Scowcroft, G., Hawkins, A., Popper, A. N., 2013. Report of the Workshop on International Harmonisation of Approaches to Define Underwater Noise Criteria. No. C197.13. IMARES Wageningen UR.

Lurton, X., 2002. An Introduction to Underwater Acoustics: Principles and Applications. Praxis Publishing Ltd, Chichester.

Mackenzie, K. V., 1981. Nine term equation for sound speed in the oceans. The Journal of the Acoustical Society of America 70 (3), 807-812.

Marine Management Organisation, 2015. Modelled Mapping of Continuous Underwater Noise Generated by Activities. A report produced for the Marine Management Organisation. MMO Project No: 1097.

McKenna, M. F., Ross, D., Wiggins, S. M., Hildebrand, J. A., 2012. Underwater radiated noise from modern commercial ships. The Journal of the Acoustical Society of America 131 (1), $92-103$.

Merchant, N., Brookes, K., Faulkner, R., 2016. Underwater noise levels in UK waters. Scientific Reports 6, 36942. assess the impact of coastal developments on marine mammals. Marine Pollution Bulletin $78(1-2), 85-95$. 
MMPA, 1972. US Marine Mammal Protection Act. 16 U.S.C. Sec. 1361 - 1421.

URL http://www.nmfs.noaa.gov/pr/laws/mmpa/

National Geophysical Data Center, 2006. 2-minute gridded global relief data (etopo2) v2.

Neenan, S. T. V., White, P. R., Leighton, T. G., Shaw, P. J., 2016. Modeling vessel noise emissions through the accumulation and propagation of automatic identification system data. Proceedings of Meetings on Acoustics 27 (1), 070017.

NURC, 2008. Sonar Acoustics Handbook. NURC, La Spezia.

Pingree, R., 1980. Chapter 13: Physical Oceanography of the Celtic Sea and English Channel. Elsevier Oceanography Series 24, 415-465.

Popov, V. V., Supin, A. Y., Rozhnov, V. V., Nechaev, D. I., Sysuyeva, E. V., Klishin, V. O., Pletenko, M. G., Tarakanov, M. B., 2013. Hearing threshold shifts and recovery after noise exposure in beluga whales, Delphinapterus leucas. The Journal of Experimental Biology 216 (9), $1587-1596$.

Porter, M., Henderson, L., 2013. Global Ocean Soundscapes. In: Proceedings of Meetings on Acoustics. Vol. 19. Acoustical Society of America, p. 010050.

Richardson, W., Greene, C., Malme, C., Thomson, D., 1995. Marine Mammals and Noise. Academic Press, San Diego.

Robinson, S. P., Lepper, P. A., Hazelwood, R. A., 2014. Good Practice Guide for Underwater Noise Measurement. NPL Good Practice Guide No. 133. National Measurement Office, Marine Scotland, The Crown Estate.

Rolland, R. M., Parks, S. E., Hunt, K. E., Castellote, M., Corkeron, P. J., Nowacek, D. P., Wasser, S. K., Kraus, S. D., 2012. Evidence that ship noise increases stress in right whales. Proceedings of the Royal Society B: Biological Sciences 279 (1737), 2363-2368.

Sertlek, H., Binnerts, B., Ainslie, M. A., 2016. The effect of sound speed profile on shallow water shipping sound maps. The Journal of the Acoustical Society of America 140, 84-88.

Sertlek, H. Ö., Ainslie, M. A., 2014. A depth-dependent formula for shallow water propagation. The Journal of the Acoustical Society of America 136 (2), 573-582.

Shapiro, G., Chen, F., Thain, R., 2014. The effect of ocean fronts on acoustic wave propagation in the Celtic Sea. Journal of Marine Systems 139, 217-226.

Simpson, J., Sharples, J., 2012. Introduction to the physical and biological oceanography of shelf seas. Cambridge University Press, Cambridge.

Urick, R., 1983. Principles of Underwater Sound, 3rd Edition. Peninsula Publishing, Los Altos. 
Van der Graaf, A. J., Ainslie, M. A., André, M., Brensing, K., Dalen, J., Dekeling, R. P. A., Robinson, S., Tasker, M. L., Thomsen, F., Werner, S., 2012. European Marine Strategy Framework Directive Good Environmental Status (MSFD-GES): Report of the technical subgroup on underwater noise and other forms of energy.

Veirs, S., Veirs, V., Wood, J., 2015. Ship noise in an urban estuary extends to frequencies used for echolocation by endangered killer whales. PeerJ 4, e1657.

Wale, M. A., Simpson, S. D., Radford, A. N., 2013. Size-dependent physiological responses of shore crabs to single and repeated playback of ship noise. Biology Letters 9 (2), 20121194.

Wales, S. C., Heitmeyer, R. M., 2002. An ensemble source spectra model for merchant ship-radiated noise. The Journal of the Acoustical Society of America 111 (3), 1211-1231.

Wang, L., Heaney, K., Pangerc, T., Theobald, P., Robinson, S., 2014. Review of Underwater Acoustic Propagation Models. NPL Report AC 12. National Physics Laboratory.

Williams, R., Wright, A., Ashe, E., Blight, L., Bruintjes, R., Canessa, R., Clark, C., Cullis-Suzuki, S., Dakin, D., Erbe, C., Hammond, P., Merchant, N., O’Hara, P., Purser, J., Radford, A., Simpson, S., Thomas, L., Wale, M., 2015. Impacts of anthropogenic noise on marine life: Publication patterns, new discoveries, and future directions in research and management. Ocean \& Coastal Management 115, 17-24.

Wittekind, D. K., 2014. A simple model for the underwater noise source level of ships. Journal of Ship Production and Design 30 (1), 1-8. 